\title{
The Reform of Higher Education through Alternative University Teaching Models
}

\author{
Stoyan Denchev, Ivanka Pavlova, Miriyana Pavlova \\ State University of Library Studies and Information Technologies SULSIT, Sofia, Bulgaria \\ Email:s.denchev@unibit.bg, i.pavlova@unibit.bg,m.pavlova@unibit.bg
}

Received 15 January 2016; accepted 22 February 2016; published 26 February 2016

Copyright $@ 2016$ by authors and Scientific Research Publishing Inc.

This work is licensed under the Creative Commons Attribution International License (CC BY). http://creativecommons.org/licenses/by/4.0/

(c) (i) Open Access

\section{Abstract}

The current paper presents the results of a project on distance learning teaching methods of the State University of Library Studies and Information Technologies, Sofia, Bulgaria (SULSIT). The scope of the analyzed project refers to the innovative educational environment, developed throughout the System for Knowledge Management and proven with its efficiency. One of the basic goals is introduction of the Cloud Computing structure that serves as an information and educational environment not only to students, but also for administrative purposes (throughout information dessimination on admission campaigns, curricula, syllabuses, exam dates, exam results, course fees, cloud information board for events, seminars, lectures and conferences), as well as an educational ambience with the potential to help students develop their subject matter and specialty competence. As an outcome of the research and on the basis of the project results, several new programs have been implemented into the MA degree programs Library and Information Studies, Printing Communications and Cultural Heritage Sciences at the Faculty of Library Studies and Cultural Heritage (FLSCH) of SULSIT.

\section{Keywords}

SULSIT, Educational Reforms, New Distance Learning Technologies, Alternative University Models, Cloud Computing in Education

\section{Introduction}

The goal of the current paper is to illustrate the importance of the Cloud Computing Systems, their application in Distance Learning Models as an alternative and major step in creating innovative University environment. The paper outlines DL teaching models used as a basis for implementation or Higher Education reforms. Several high level research projects related to distance education of the State University of Library Studies and Informa- 
tion Technologies (SULSIT), Sofia, Bulgaria, concerning the development of e-Educational Models have been described within the research, for better interpretation of the above statement. Since one of the main tasks of SULSIT is to create conditions to ensure high quality education in an environment of modern electronic technologies and to provide full technical and technological assistance and support for its academic stuff, tutors and lecturers, administrative stuff and students in the educational process through contemporary information and communication technologies, it is essential for university to participate in e-education projects and to apply the best EU practices in this direction (Peteva, 2009). The overview below shows in details the development of SULSIT's capacity in the field of modern educational technologies, i.e. Distance learning.

\section{Distance Learning in Library and Information Sciences, Printing Communications and Cultural Heritage Sciences}

In October 2012, a contract was signed and the realization of a project on "Distance Learning in Library and Information Sciences, Printing Communications and Cultural Heritage Sciences” started. The project was implemented with the financial support of Operational Programme "Human Resources Development", grant scheme BG051PO0001-4.3.04 "Development of Electronic Forms of Distance Learning in Higher Education”, financed by the European Social Fund and the European Union with duration of 24 months.

Contractor of the project was the Faculty of Library Studies and Cultural Heritage at the University of Library Studies and Information Technologies (FLSCH) at SULSIT.

The overall objective of the project was the development of distance educational programmes in MA degree in Library and Information Studies, Printing Communications and Cultural Heritage studies as well as the education of students of the FLSCH at SULSIT. Through this project, new programmes for distance learning in the higher education system in the Republic of Bulgaria are offered, thus meeting the genuine needs for professionals in the library and information, the publishing and the cultural spheres.

The specific objectives of the project were:

1) Implementation of a strategy for the application of e-forms for distance learning in Library sciences, Library management, Book and society, Cultural and historical heritage in the structure of FLSCH as well as the professional development of the tutorial staff;

2) Development and implementation of a learning process after four new curricula and enriching the educational content of two other distance learning programmes. Generating educational content and compiling electronic and multimedia reference books;

3) Establishing an "E-library in Library and Information Studies, Communications and Cultural Heritage" in support of distance learning (Pavlova, 2007);

4) Developing an e-repository forcourse theses and master theses, which will serve as a future depository of SULSIT;

5) Promoting of the project by a PR-campaign, including four seminars and one conference, dedicated to the achievements of the project. Multiplying the results at institutional and national levels;

6) Implementation of the 2012 version of e-distance learning platform ILIAS, team training, adapted training materials;

7) "Training of eight trainers" from the tutorial staff of the FLSCH for applying electronic forms of distance learning;

8) Implemented electronic portfolio of informal e-teaching of the tutorial staff at the FLSCH;

9) The "trainers" trained 30 people from the academic, administrative and technical staff of the FLSCH for applying e-forms of DL, etc.

The DLC (Distance Learning Centre) team actively supported and assisted in the realization of the project "Distance Learning in Library and Information Studies, Printing Communications, and Cultural Heritage Studies." Moreover, it carried out the creation of the structure and main components of the MA programmes in the already installed an updated version of ILIAS (Integriertes Lern-, Informations-und Arbeitskooperations-System) platform, and the transfer of materials from the old version of ILIAS to the new one on two of the MA programmes, so that they could subsequently be updated by the tutors (Denchev \& Pavlova, 2010).

\section{Development of a System for Knowledge Management}

In April 2013, a contract was signed and the implementation of the project "Development of a System for 
Knowledge Management in the Faculty of Information Studies (FIS) at SULSIT” was started (Peteva, 2008). This project was implemented with the financial support of Operational Programme "Human Resources Development" grant scheme BG051PO0001-4.3.04 "Development of Electronic Forms of Distance Learning in Higher Education”, financed by the European Social Fund of the European Union. The project duration was 24 months.

Contractor of the project was the Faculty of Information Studies at the University of Library Studies and Information Technologies.

The overall objective of the project aimed at improving the training forms and including innovative approaches, which contribute to enhancing the quality of skills and knowledge and to the realization of young people in the sphere of education and science. A direct result of the implementation of this objective was boosting the research potential in SULSIT.

Specific objective of the project was to create better conditions for increase in the qualification of the academic staff, the expert staff, as well as the students in the various majors at SULSIT.

The project tasks were:

1) Development of an information system for knowledge management.

2) Creating adapted curricula and reference books for electronic forms of distance learning.

3) Training of the tutors and experts of the FIS for implementing the developed information system for knowledge management.

4) Introducing the students of the FIS to the opportunities of the information system.

5) Purchase of a server and equipment for a computer seminar with 20 computers, etc.

In this regard, part of the DLC team and the tutors at SULSIT took part in the implementation of this project. SULSIT tutors wrote textbooks for 52 subjects, with ISBN copyrights, as part of the tasks on this project.

As a consequence of the implementation of the projects and the policy of SULSIT for the development of distance learning, the DLC has expanded its activity and since 2014/2015 the university started admitting students in six MA and one BA programmes.

\subsection{Cloud Computing University Model}

Cloud computing is a term used to describe a virtual environment where all the necessary computer resources, software programmes, information content and the actions on their maintenance and provision are concentrated, which does not require the end user to know the real location of such systems. In fact, these are quite real material resources but it is because we do not know where they are, to our minds they are mostly virtual and are located somewhere in the clouds, hence the name of the term. In this way, the concept of a cloud turns into a basis for innovative solutions, new business models and educational opportunities allowing a more effective use of the Internet by each and every user (Pavlova, 2013).

It is widely discussed today the opportunity to use cloud structures in the university administration and educational programmes, projects and training courses. With the necessary IT resources, IT systems and IT experts, it is now possible to introduce cost effective educational practices; the investments that would have been necessary to serve various university departments and other university units and structures could be combined to form a centralised cloud model that all university structures take advantage of, thus economising on scale (Pavlova, 2015). The cloud structure serves as an information and educational environment to students. It is of use not only for administrative purposes (information on admission campaigns, curricula, syllabuses, exam dates, exam results, course fees, cloud information board for events, seminars, lectures and conferences) but also for an educational ambience with the potential to help students develop their subject matter and specialty competence. It enables the students:

1) To work directly with concepts, notions and environments; to accept the role of an experimenter, to check out hypothesis and draw conclusions on the basis of gathered information, to work in conditions of a group or a team. This allows for the deeper acquisition of ideas and establishing links between new concepts and previously studied material;

2) To work in conditions of the real world. The cloud computing educational environment allows the more exact modelling of different situations and conditions of the real world where eventually new knowledge will be applied;

3) To flexibly use information and communication technological resources, to work with the studied material in 
different ways and applying various approaches, to create and supply production demonstrating the results of the training process in particular forms and formats. Thus, the information and education environment created within the cloud representing a space for individual modifications of the people (tutors and students) in educational aims is an effective means for the development of the knowledge and knowledge management of the students. In the light of the impact of the changes of education in the European integration of the South East region, the building of information educational environments does not only refer to the aspects of the professional activity of tutors, but the specific activities in the virtual environment of students and their independent field of study in the preparation of a wealthy knowledge economy of the region (Chantov, 2013).

A good solution to the outlined ideas on cloud computing in educational environments would be the creation of a site within the local intranet of the university with file archive sections, a reference system, a learning materials system, an information search system, as well as communication opportunities between users. The library of reference materials should contain not just text information but also diagrams, schemes, clusters, illustrative materials, video fragments, audio files. The most significant of all, perhaps, is the organization of the workstation of the student. Each course participant should be able to create their own calendar of events, to draw a graphic scheme of their individual route of participation in the course of study, to select the most suitable for them means of communicating and publishing of their work. In order to raise the effectiveness of the process of developing professional competences and life-long learning skills, the resource database of the cloud should include products as a result of the scientific studies of students-competitive exhibitions, site publications of the most innovative and creative scientific research results, stimulating learning activity publications, and raising motivation events and case-studies. The results of student activity especially those of post-graduates could serve as a role model for the students-to-come. The analysis of the results from the activity archived production would allow the assessment of the educational quality in the cloud. The works of students could be saved in the forum of respective sections of the archive; the results of the completed tasks can be fixed in different student blogs and the best creative works can be posted in special sections.

In addition to the above-mentioned projects, we would like to highlight the following related aspect.

\subsection{The Portfolio as an Alternative Assessment Tool of Educational Processes}

An alternative way to assess students' achievements in the context of alternative educational models and the impact of reforms of education in the EU integration processes of the South East region is the Students' Portfolio. There is no better way of measuring the suggested shift in the educational paradigm: from ACCREDITED QUALIFICATION to CERTIFIED SKILLS (Global Education \& Skills Forum, Dubai-2013) than measuring competencies and the competence of future specialists, a leading criterion for the quality of the university courses for what determines the necessity of new pedagogic dimensions objectively reflecting students' achievements. The essence lies in the idea that the portfolio as a diagnostic tool is based on the idea of the competence approach and the knowledge economy society. The portfolio is seen as a kind of authentic assessment applied in the practically oriented education and projecting the assessment of the formation of the necessary skills and knowledge of the personality of the student in conditions or situations close to real life situations. Unlike the testing approach, which gives no complete and full picture of the students' level of preparation, the authentic assessment or the "student centred learning" seems from this angle much more transparent and standardized. An example of the application of the portfolio as an alternative to traditional assessment tools could be the so-called "achievement files", used in educational institutions in Germany in order for each student to build up evidence of the level of achievement of each step of the educational process and the acquisition of practical skills.

\section{Conclusions}

It becomes obvious that distance learning has a prospect for the future since it provides many advantages: student mobility; opportunity for personal training pace; training at a time, convenientfor the student; workbased learning; significant decrease in costs; continuing training tailored to meet the requirements of disadvantaged students, etc.

This form of training is very suitable especially for those who work and are restricted in their ability for a prolonged absence from work as well as for people with special educational needs or disadvantaged people.

In this regard, distance learning has increased widely and a number of universities have established distancelearning centres with the aim of organizing this type of activity. 


\section{References}

Chantov, V. (2013). The Portfolio-A Method for Measuring of the Academic Achievement of Students in Foreign Language Education. In Proceedings of Xth National Scientific Conference with International Participation: The knowledge Society and the Humanism of the XXI Century (pp.549-565). Sofia: Za bukvite-o pismeneh.

Denchev, S., \& Pavlova, Iv. (2010). Analysis and Management of University Information Environment: Information Behaviour and Culture. Sofia: Za bukvite-o pismeneh.

Pavlova, D. (2013). Academic Institutions as An Environment for Realization of the E-Government. In Scientific Conference with International Participation, Youth in Science-Investment in the Future, Sofia, 18-20 October 2013, 123-130.

Pavlova, D. (2015). Government, in the Clouds. Proceedings of VIIth International Scientific Seminar, Modern Dimensions in European Education and Research Area, Bulgarian-British Cultural Communications, London, 27-28 May 2013, 29-34. Sofia: Za bukvite-o pismeneh.

Pavlova, Iv. (2007). Digital Libraries and Access to Information Resources: Digital Collections Protection. Sofia: Za bukvite-o pismeneh.

Peteva, I. (2008). Information Sitizen: Information Publicity and Information Security. Sofia: Za bukvite-o pismeneh, 200 p.

Peteva, I. (2009). Informaction Access Right and Information Competence in the Contemporary Social Environment. In I. Pavlova (Compiled), Information Competence Handbook (pp. 21-26). Sofia: WINI-1837. 